Buor, D.

Mothers education and childhood mortality in Ghana.

Health Policy: 64, 2003, nr. 3, p. 297-309

\begin{tabular}{|l|l|}
\hline Postprint Version & 1.0 \\
\hline Journal website & http://dx.doi.org \\
Pubmed link & $\begin{array}{l}\text { http://www.ncbi.nlm.nih.gov/entrez/query.fcgi?cmd=Retrieve\&db=pubmed\&dop } \\
\text { t=Abstract\&list uids=12745169\&query hl=13\&itool=pubmed docsum }\end{array}$ \\
\hline DOI & $\underline{10.1016 / \text { S0168-8510(02)00178-1 }}$
\end{tabular}

*Tel.: +/233-51-60182; fax: 233-51-60137. E-mail address: danielbuor@yahoo.com (D. Buor).

\title{
Mothers’ education and childhood mortality in Ghana
}

\author{
DANIEL BUOR *
}

Faculty of Social Sciences, Kwame Nkrumah University of Science and Technology, Kumasi, Ghana

\begin{abstract}
The significant extent to which maternal education affects child health has been advanced in several sociodemographic- medical literature, but not much has been done in analysing the spatial dimension of the problem; and also using graphic and linear regression models of representation. In Ghana, very little has been done to relate the two variables and offer pragmatic explanations. The need to correlate the two, using a regression model, which is rarely applied in previous studies, is a methodological necessity. The paper examines the impact of mothers' education on childhood mortality in Ghana using, primarily, Ghana Demographic and Health Survey data of 1998 and World Bank data of 2000. The survey has emphatically established that there is an inverse relationship between mothers' education and child survivorship. The use of basic health facilities that relate to childhood survival shows a direct relationship with mothers' education. Recommendations for policy initiatives to simultaneously emphasise the education of the girl-child, and to ensure adequate access to maternal and child health services, have been made. The need for an experimental project of integrating maternal education and child health services has also been recommended. A linear regression model that illustrates the relationship between maternal education and childhood survival has emerged.
\end{abstract}

\section{INTRODUCTION AND THE PROBLEM}

The argument that the education of women has greater impact on the survival of their children has been advanced in several health care literature. In Ghana, however, very little has been done to organise scattered information into a comprehensive treatise. Although there have been reports on surveys on child mortality, and of their mothers' education in survey reports, notably, the Ghana Demographic and Health Surveys (GDHS), such reports have not been organised and comprehensively analysed for the purpose of discovering policy implications.

Nor have there been efforts to examine the childhood mortality and fertility patterns from geographical perspectives, which is urgent in structuring a comprehensive policy framework. Third, very little has been done in developing a graphic (linear regression/curve estimation) model to depict the relationship. Studies have tended to be either purely qualitative, or using simple descriptive statistics to analyse the relationship, which are not adequate in establishing reality.

In sum, though there have been surveys on childhood mortality and maternal education, with the latter constituting the independent variable, not much, especially in Ghana, has been done in offering explanations using the geographical approach and a regression analysis. There is also the need for a model of establishing a strong foundation for a sound child health and maternal education. It is to bridge such a research gap, and to discover a strategy for a sustainable maternal education and child 
health that it became necessary to examine the relationship between childhood mortality and mothers' education in Ghana, using primarily 1998 GDHS and World Bank data.

The rate of infant and child mortality is very alarming in Africa and developing countries. The World Bank [1] indicates that infant mortality rate for sub-Saharan Africa is 92/1000; and for under-five mortality rate, it is as high as 151/1000. This is rather high compared with 26/1000 and 31/1000 for infant mortality and under-five mortality rate respectively for upper-middle-income countries. So important is child survivorship to general health attainment of countries that the World Health Organisation has identified it between the two measures of health attainment at the country level in terms of the average level of population health and the distribution of population health or health equality. These are disability-adjusted life expectancy and the index of equality of child survival [2].

The role of the mothers' education in child survivorship has been made evident by several literature on health in developing countries. In sub-Saharan Africa, whereas the proportion of childhood deaths of mothers with $1-3$ years of formal education is 0.92 , it is 0.77 for those with 4-6 years of schooling; and for those with 7+years of schooling, it is 0.56 [3].

The role of maternal education in childhood survival could be seen in their use of prenatal and child health care services. In Thailand, Raghupathy found that secondary education was the most consistent predictor of prenatal care use [4]; and in Vietnam, Swenson et al. discovered that the woman's educational level and total number of living children were the most significant predictors of prenatal care utilisation [5]. With regard to childcare, which is a significant factor in child survival, the educated woman is keener. In Ghana, whereas $42.2 \%$ of mothers without formal education immunised their children against BCG, DPT, polio, and measles between 1989 and 1993, 86.7\% of mothers with secondary education and above did [6]. The educated and those of high socioeconomic status utilise health services more than the uneducated and those of low social class [7].

Another advantage the educated woman has is accessing income sources. Income is about the greatest impediment to the use of health facilities in developing countries [8-10]. The educated woman has a high probability of getting a job that carries good pay. The population of women is more than men, and the few educated women have access to jobs, especially in the formal sector. In Ghana, the sex ratio (ratio of male to female population) is 96.1 , with females constituting $51 \%$ of total population [11].

Education would thus give the woman the economic empowerment to be able to freely decide to take her child to hospital for health care. It is a tool to demolish the barrier to participation in family decisions. In African countries, as in Ghana, authority in the family rests largely on the man who has control over family resources, a factor that determines the use of health care. Whereas in the traditional families the man monopolises decision making, in the elite (educated) families the woman plays a meaningful role, enjoying some autonomy [12]. Yet, in Ghana, the illiteracy rate is rather high for women. Whereas the adult male illiteracy rate is $22 \%$ of those aged 15 and above, it is as high as $40 \%$ for females [13]. This inequity has serious implications for the development of women. The Government's Free Compulsory Universal Basic Education (FCUBE) programme, in which education is to be free at the basic level, has not witnessed a remarkable success. In the rural areas, especially, access to basic education is low.

In Ghana, as in several African countries, women bear the greater burden of childcare. Men relegate such responsibilities to the women, thus making their domestic burden rather enormous. On the issue of supporting children among the Akans, the largest ethnic group in Ghana, Bleek writes:

Having children, both in the sense of bearing them and in the plain sense of supporting them, is mainly a woman's affair. As we have seen, Akan men often do not support their children [14].

In Ghana, the incidence of child survivorship and education of women have their spatial perspectives. There would be variation by rural-urban, rural-peri-urban, rural-semi-urban and within urban nodes. Within urban nodes, urban core and urban periphery would tend to vary, given that residential arrangements in urban areas correlate with wealth and social status. Women of high rank in the civil and public services would tend to occupy the core sector in the metropolis. There is a great disparity in the distribution of health care facilities in Ghana. The urban areas have greater proportion of all types of health care facilities (including childcare services) in Ghana. The poor physical accessibility, 
coupled with low level education and poverty, put rural women at a disadvantage in their care for their health and that of their children.

There is yet another problem that has implications for childhood survival; and that is the lack of a national health insurance scheme that has the potential of affecting equity in access to health facilities. Health insurance has been found to exhibit a high positive association with the utilisation of health services in developing countries. In a study of the Bwamanda hospital insurance scheme in Zaire (Democratic Republic of the Congo), Criel et al. found that utilisation increased among insured patients [15]. The burden of health care on government, in the absence of a national health insurance scheme, is quite great. Resources committed to the health sector are inadequate; yet there is more concentration on tertiary health services to the detriment of primary health care.

This paper examines, using secondary sources, the impact of women's education on child survivorship in Ghana. The operating arguments are four. First, infant mortality, which is endemic in the Ghanaian society thus constitutes a serious health problem, cannot be addressed without a development of maternal education. The development of the two should therefore be simultaneous. The education of the girl-child, as a policy, should be seen in the broad perspective of creating a broader platform for dealing with child health. The second argument is that a clear policy to establish a pilot project of integration of child health and maternal education services would be urgent if a strong association between child health and maternal education were established. There is currently no such project, a factor that makes it difficult to structure a hypothesis on the two events. Such a project would form the basis for a hypothesis and an empirical survey on the emerging results. The third basis for the research is that a regression approach is needed to break the hold of simple descriptive statistics that have been the analytical tool for such surveys. The fourth argument is that studies on child survivorship and maternal education have usually missed the spatial focus. It is hoped the results would better bring to focus the impact of mothers' education on child survivorship and strategies of ensuring sustainable child health and maternal education.

\section{METHODS}

The independent variable is mothers' education, and how it relates to the promotive factors of infant and child mortality. These factors include, antenatal care, maternal nutrition, child nutrition, and postnatal care as indicated mainly by child vaccination. In antenatal care, the care provider and place of delivery have been selected for analysis. The level of education of mothers and how it relates to these variables have been examined. The dependent (outcome) variables are childhood mortality and the prevalence of childhood diseases namely, respiratory tract infection, fever and diarrhoea. The morbidity conditions are analysed to find out how they reinforce mortality conditions. The relationship between these variables is time-based. The 1998 GDHS data is largely used. The study examines the spatial dimension, rural-urban variations. Thus the study assumes a spatio-temporal dimension.

The 1998 GDHS was a nationally representative survey of 4843 women aged 15-49 and 1546 men aged 15-59. ${ }^{1}$ The survey covered the 5-year period of 1993-1998. The GDHS data is based on a twostaged stratified, nationally representative sample of households [16]. At the first stage of sampling, 400 enumeration areas (EAs) were selected using systematic sampling with probability proportion to size (PPD) method. The EAs were selected from a subsample of 1000 EAs, made up of 138 urban EAs and 262 rural EAs. A complete household listing operation was then carried out in the EAs having less than 500 households. EAs with 500 or more households were segmented into two or three equal parts with a minimum of 200 households, and one segment was selected randomly. The list of households provided a sampling frame for the second stage selection. At the second stage of sampling, a systematic sample of 15 households per EA was selected in all regions, except in the Northern, Upper West and Upper East Regions, where the number per EA was increased to $20{ }^{2}$ The household response rate, eligible woman response rate and overall response rate for women were as high as 99.1, 97.4, and 96.6\%, respectively [17].

With specific reference to infant and child mortality on which the study is based, the quality of data could be said to be credible. The reliability of mortality estimates depends on the extent to which date

\footnotetext{
1 For the purpose of this paper, women data is used.

2 There are ten regions in the country. These three regions are the less densely populated and the most economically and socially deprived.
} 
of birth and age at death are accurately reported and recorded and the completeness with which child deaths are reported. Omission of births and deaths has a direct effect on mortality estimates whilst displacement of dates could affect mortality trends. Age misreporting at death may distort the pattern of mortality. There was fairly complete information on the date at death for all children. There was however some evidence of omission of deaths in the most recent 5-year period. There is also some evidence of misreporting of birth dates. Early infant deaths however were not found to have been under reported [18]. The quality of data could therefore be ascertained. The quality of mortality data could further be ascertained by the low level sampling errors as indicated in Table 1.

\section{[ TABLE 1$]$}

Given the number of cases $(N)$ the sample error (SE) and relative error (RE) are rather insignificant, so are an indication of the quality of the sample, which justifies the credibility of the results.

A simple linear regression model (curve estimation) has been structured to show the relationship between mothers' education and infant mortality. The codes used for the levels of education are as follows: no formal education-0; primary education-1; secondary education-2; Middle/ Junior secondary school and above-3. Beta coefficient and adjusted coefficient of determination $\left(R^{2}\right)$ derived are -0.898 and 0.710 , respectively, which are quite high to 468 .

\section{EDUCATION OF WOMEN AND CHILD HEALTH IN DEVELOPING COUNTRIES}

The positive relationship between women's education and child health in developing countries rests upon a sound theoretical foundation. A great barrier to the use of scientific health services in developing countries is superstition, which is a function of illiteracy. There is a strong tendency to utilise traditional medicine and self-medication that are major sources of child mortality. The attainment of more formal education is very urgent for women in developing countries in overcoming the cultural constraints and prohibitive social norms [20]. The uneducated use more of traditional medicine [21], with concomitant risks to health. In sub-Saharan Africa, the trend is that, the more the number of years spent in school by women, the higher the survival rate of their children [3].

In a study of the differential effect of mothers' education on mortality of boys and girls in India, Katherine and George found that improved mothers' education reduced mortality at all ages below five years for both sexes [22]. In another study on mothers' education and survival of female children in a rural area in Bangladesh it was found that for boys, a change in mothers' education from no schooling to 1-5 years resulted in reducing the predicted risk of death by $45 \%$, while for girls the reduction came to only $7 \%$. Similarly, a change in mothers' education from no schooling to six or more years of schooling resulted in a reduction of risk of $70 \%$ for boys, whilst for girls it was only $32 \%$ [23]. The educated woman would not use health services recklessly, but effectively through compliance with the directions of the physician. The educated mothers are more committed to following the instructions of the physician to ensure recovery from illnesses. They are more likely to spend a longer time with the physician, explaining the problem and listening to his instructions. They could record their problems at home before coming to see the doctor, and could also record instructions given by the doctor. They have a high probability of reporting back to the doctor if they or their children are not recovering [24].

An important factor in the healing process is going by physicians' instructions concerning dosage levels, in which the educated mother has an advantage. She can read and know the times to take a dosage, and the quantity to take at a time. She can also detect where a particular drug has expired, so should be disposed of. In most developing countries where foreign language is used as the national medium of communication, she could overcome the language barrier when she goes to the hospital for treatment. Such languages in which health literature is written are better able to explain health conditions than the local languages that lack the appropriate definition of terminologies.

The referral system is least respected in developing countries where illiteracy and poverty predominate. In a study of risk approach in antenatal care: evaluation of the referral compliance in the Kasongo District in Eastern Zaire, Dujardin, et al. gathered that the referral success rate was 33\% [25]; and the main explanation was the low socioeconomic status of the residents in the area. The educated woman is thus more likely to go by referral instructions in getting her child treated. 
By complying with physicians' instructions, the educated woman has a higher probability of recovering from ailments, and ensuring the survivorship of her children. Bor, et al. in a study of the socio-economic disadvantage and child morbidity in Australia concluded that, there was a consistent pattern with children of the most socioeconomically disadvantaged mothers manifesting the worst health [26]. Yach and von-Schirnding share the view that the education of women is strongly related to child survival [27].

The chief stimulus to health transition programmes has been found to be the demonstration of significant differentials in the survival of children by the education of their mothers [28], and the education of women has almost as powerful an effect on whole societies in improving child survival at every level of mothers' education. A United Nations study of 15 developing countries on mothers' education and child survival concluded that an additional year of mothers' schooling reduces child mortality by $6.8 \%$ [29].

Education of women, therefore, is very crucial to the survival of their children. It is therefore urgent that health issues in developing countries take into consideration the education of the girlchild who will grow to be a mother and rearers of children. It is imperative that a policy is initiated to ensure the literacy of the girl-child.

\section{STATUS OF CHILDHOOD MORTALITY}

The rate of infant mortality in Ghana has been declining steadily, though high when compared with the middle-income economies that Ghana is aspiring to attain. In 1975, it was 99.6/1000 live births [30]. This declined 10 years later in 1985 to 77.2/1000 live births. In 1996, 11 years later, it further decreased to 56.7/1000 live births. The status of infant health in Ghana is better compared with countries in West African sub-region, and among low-income countries in which Ghana falls. In 1998, whereas the rate for Ghana was 65/1000 live births [31], it was 88 for Cote d'Ivoire and 104 for Burkina Fasso [31]. It was 68/1000 for lowincome countries, and 92 for Sub-Saharan Africa [31].

Results from the 1998 GDHS, in combination with data from the 1993 GDHS show a marked decline in infant and under-five mortality. Infant mortality declined from 100/1000 to 57/1000 live births in the last 20 years [30].

The possible factors responsible for the steady decline are, among others, the rate of vaccination against the six childhood killer diseases, declining female illiteracy, use of antenatal and postnatal facilities, and improvement in childhood nutrition. The proportion of children fully vaccinated before age one increased from 43\% in 1993 to 51\% in 1998 [32]. Moreover, the gap in female-male difference in educational participation is narrowing, with more females attaining secondary and tertiary education [33]. The government policy of FCUBE has had some minimum impact on society by ensuring that as many females as possible of school-going age get enrolled, the bottlenecks in the policy notwithstanding.

Perhaps, the significant improvement in the use of antenatal and postnatal facilities, and improvement in childhood nutrition are the most significant factors in childhood survival in Ghana. The percentage of births to women receiving antenatal care from a doctor, nurse or midwife is $89 \%$, up from 86\% in 1993 [34]; and the proportion of children breast-fed within 1 hour and 1 day has markedly increased [35].

\section{CHILDHOOD MORTALITY AND MOTHERS’ EDUCATION}

Education of mothers shows an inverse relationship with childhood mortality. Children of mothers with higher education show a low mortality rate, as indicated in Table 2.

\section{[ TABLE 2 ]}

It is clear from the data that there is an education-lower mortality gradient. Children of mothers of higher education experience lower mortalities at all levels of childhood mortality. The exceptions are neonatal mortality and infant mortality in which children of mothers of primary education exceeded those of no education. This follows a trend in developing countries. Women with mere primary education, and staying in the rural areas, who are distant from urban life with its elitism and modernism, will tend to slip into the condition of illiteracy. There will, however, be differences based 
on marital partners. Educated husbands of women with no education are more likely to influence the attitudes of their wives in childcare.

Beta coefficient and adjusted coefficient of determination $\left(\mathrm{R}^{2}\right)$ derived are -0.898 and 0.710 , respectively, which are quite high. A graphic model (linear regression/curve estimation) emerges from the relationship between infant mortality and mothers' education (Table 2) as depicted in Fig. 1.

\section{[ FIGURE 1 ]}

The model clearly depicts a strong inverse relationship between mothers' education and infant mortality. As mothers' education increases, child mortality rate declines, and vice versa. This relationship has been the trend in developing countries.

There are differences in mortality by place of residence. Childhood mortality at every level is lower in the urban than the rural areas. Infant and child mortalities for rural and urban areas in Ghana are indicated in Figs. 2 and 3, respectively.

\section{[ FIGURES 2 AND 3 ]}

For infant mortality, the rate is 42.6/1000 live births for urban areas, and 57.5/1000 live births for rural areas. For under-five mortality, the rates are 78.6/1000 and 122/1000 live births for urban and rural areas, respectively. Thus, the differences in childhood mortality between the urban and rural areas are significant. The mortality by place of residence could be linked with the education of mothers. There is a dichotomy in the level of educational attainment by rural-urban in Ghana and other developing countries. Illiteracy rate is higher in the rural areas than urban areas. Illiteracy is thus a function of place of residence, with the rural areas experiencing a greater rate. Illiteracy rate of mothers in the rural areas is higher than the urban areas. This is due to lack of adequate educational facilities in the rural areas, rural poverty and low standards of living, and the cultural notion that the place of the woman is the home, so there is no need for a woman to aspire towards higher educational attainments.

The other reasons for the high childhood mortality in the rural areas, apart from the illiteracy of mothers which forms the main hypothesis for this paper is that, there are fewer health facilities in the rural areas, especially for maternal and child health. Other factors that could influence childhood mortality in the rural areas are poverty, reliance on traditional medicine and poor physical access to health facilities. Moreover, access to non-clinical services like immunisation is poor.

\section{USE OF HEALTH PROMOTIVE FACTORS AND SERVICES AND MOTHERS' EDUCATION}

Mothers' education also shows a positive relationship with the use of facilities that promote the health of the child. Factors that have been identified for the purpose of this paper are antenatal care, nutrition of both child and mother, and childhood vaccination. For antenatal care, the factors considered are maternal vaccination, place of delivery, and the provider.

\subsection{Antenatal care}

The health of the mother during and after pregnancy has a significant impact on the health of the child. Therefore, in the analysis of childhood mortality, the health of the mother needs to be considered. One of the health problems that affect mother and child, which is a factor of maternal and child mortality, is tetanus. The percentage of births to mothers who received two doses or more tetanus toxoid injections during pregnancy was higher for those with secondary education and above than for other levels of education as indicated in Table 3.

\section{[ TABLE 3 ]}

There is a direct relationship between the level of mothers' education and tetanus toxoid vaccinations. The numbers of vaccinations increase with increase in the level of mothers' education for two or more doses, which is the requirement by the health authorities. There is, on the other hand, 
an inverse relationship between the level of mothers' education and non-participation in the vaccination; the higher the level of education, the lower the non-participation rate.

The proportion of mothers delivering at health facilities shows a direct relationship with their level of education. More mothers with secondary education and above deliver at health facilities than those of the other levels of education (Fig. 4). On the contrary, there were more mothers of no education delivering at home (Fig. 5).

\section{[FIGURES 4 AND 5 ]}

Deliveries at a health facility depend upon the ability to pay, which is a predicament for the rural poor. In the rural areas in Ghana, traditional birth attendants (TBAs) operate on a larger scale. Poor rural women find the TBAs a welcome solace because of the high cost of delivering at health facilities. This factor is confirmed by the rural-urban disparity in delivery at home, which is $22.7 \%$ for urban women and $66.2 \%$ for rural women. This problem calls for a policy to ensure that rural women have easier access to antenatal services.

\subsection{Maternal and child nutrition}

Maternal nutrition is very urgent in ensuring the nutrition of the child, especially, regarding breastfeeding. The percentage of women whose body mass index was less than $18.5 \mathrm{~kg} / \mathrm{m}^{2}$, the standard used in the survey, was greater for women with no education than for those with secondary education and above. Whereas it was $12.7 \%$ for those with no education, $11.2 \%$ for those with Primary education, and $10.8 \%$ for those with Middle School/JSS education, it was $5.8 \%$ for women with Secondary education and above [39]. Whereas the difference between those with secondary education and above was significant, it was not significant between the other levels. Nutrition calls for financial resources, and for that matter, adequate income, which could be guaranteed for those with higher education. ${ }^{3}$ There is a significant difference between rural and urban. Whereas it is $5.4 \%$ for urban areas, it is $13.4 \%$ for the rural [39]. The poverty factor explains this dichotomy.

Breastfeeding is, however, not encouraging, and does not show a significant difference by education. Among children under 3 years of age, median breastfeeding duration in months showed no significant difference by mothers' education. Whereas for exclusive breastfeeding, it was 0.6 for those with no education and primary education, it was 0.7 for those with Middle/JSS education and Secondary education and above. There was, however, a significant difference by rural-urban, with the median for the urban being 2.1, and for the rural being 0.6 [40]. Whereas for those with secondary education and above, the pressures of formal employment may make it difficult for exclusive breastfeeding, lack of education for the illiterate makes it difficult for them to embrace exclusive breastfeeding. It is popularly held, especially in the rural areas, that exclusive breastfeeding could lead to dehydration of children, and affect their growth.

\subsection{Childhood vaccination}

Vaccinations show a significant difference by mothers' education. It shows a steep no educationeducation gradient, irrespective of the immunisation campaigns mounted by governments for the last two decades. The percentage of children who are fully vaccinated, having received BCG, measles and three doses of DPT and polio (excluding polio 0 ) according to the level of their mothers' education, is indicated in Fig. 6.

\section{[ FIGURE 6 ]}

\section{DISEASE PREVALENCE AND MALNUTRITION AMONG CHILDREN BY MOTHERS' EDUCATION}

The hallmark of the promotive facilities is to ensure the health of children, as evident by certain indicators. The measurement of these indicators would reinforce the mortality factor in the overall

\footnotetext{
3 In Ghana, educational level is the main determinant for employment and rank in the civil and public services. Women with no or low education find themselves in the informal sector where regular income is not guaranteed.
} 
assessment of child health, and how it relates to the education of their mothers. For the purpose of this paper, the diseases that have been selected for exhibiting a relationship with mothers' education are diarrhoea, acute respiratory infection (ARI), and fever. The malnutrition of children is also related to mothers' education. These are risk factors of childhood mortality. These risk factors and their relationship with mothers' education are respectively indicated in Tables 4 and 5.

\section{[ TABLES 4 AND 5 ]}

Whereas differences between levels of education are significant for diarrhoea and insignificant for ARI, education has no impact on the prevalence of fever. Fever is an endemic tropical disease that does not necessarily need knowledge of it or financial resources to protect oneself from it. The same applies to ARI, which could be contracted through pollution, an endemic problem in developing countries. There is a clear distinction between the illiterate mothers and those with secondary education and above in the prevalence of childhood malnutrition, with respect to heightfor- age and weight-for-age.

\section{DEVELOPMENT AND CHILDHOOD MORTALITY}

The hypothesis that could be formulated, based on research data, on the relationship between development and infant and child mortality is that childhood mortality is a function of development. Developed economies tend to have low infant and child mortality rates, whilst developing economies tend to have very high infant and child mortality rates. The infant mortality rate per 1000 live births for Ghana is 65; for low-income economies, 82, and for high-income economies, 6 [31]. The developed economies tend to have a better health care delivery system. Secondly, highincomes ensure better maternal and child nutrition and general health care. Access to better health facilities is also regular. Health insurance is a national policy for most developed economies, which ensures that the obstacle to non-attendance is removed.

Maternal welfare is closely linked with childcare. The health and social status of the mother is a strong determinant of child health and welfare, and the maternal welfare is linked with her level of enlightenment, her education. Given that literacy rate declines with economic growth, one could infer that child health is ensured in a developed economy through the education or enlightenment of the mother. This proposition buttresses the hypothesis that is being vindicated through theoretical analysis.

\section{POLICY IMPLICATIONS}

The survey has clearly identified that mothers' education has a significant impact on childhood morbidity and mortality. It could emphatically be hypothesised, going by the survey, that mothers' education exhibits an inverse relationship with childhood mortality. The model that emerges is that mothers who have an appreciable level of education are able to cater better for the health needs of their children. They have access to higher incomes through employment with good pay. With relatively better access to financial resources, they have better access to antenatal and postnatal services, and are in a better health condition to ensure better health of their children.

The other issue with the women-education-child health syndrome is a policy to ensure easy access to antenatal and postnatal health services. The gap in the distribution of such services between the rural and urban areas must be bridged. Access roads to rural health centres must be improved to increase accessibility, whilst measures must be taken to increase the quantity and quality of rural health services. Primary health care services must be emphasised.

The government's FCUBE that intends, among other objectives, to get a significant proportion of female children in school, has not achieved a significant success. Whereas the adult illiteracy rate for males is $22 \%$, it is $40 \%$ for females [13]. Currently, basic education, that is supposed to be free, is not free after all. Parents are responsible for providing certain basic infrastructure for schools and buying basic textbooks for their wards. The examination fees for the Basic Education Certificate Examination ${ }^{4}$ and other fees charged have discouraged several parents from taking their children to school. In the event of educational sponsorship, parents, especially those in the rural areas, are more inclined to

4 It is the final examination taken by Junior Secondary School Students for the entry into Senior Secondary School. 
sacrifice for their male children. This follows after the cultural notion that the place for the woman is the home. Government should ensure that basic education is free indeed, as defined in the FCUBE programme, and that secondary education is made accessible to the girlchild.

The rural secondary schools must be well resourced, in terms of personnel and equipment to attract the right calibre of academic staff. Since a greater proportion of girls is in the rural areas, the improvement in the facilities in the rural secondary schools would ensure that as many as those who pass the entrance examination enter.

The girl-child should be exposed to child health even from the basic level of education. The Ministries of Education, Health, Women's and Children's Affairs should structure curricula for a special education of the girl-child on health issues related to women and children. They must be exposed to reproductive and child health issues. A special class should be devoted to that, apart from the general science classes.

The Non-Formal Education programme that targets adult illiterates should be intensified. There should be an integrated programme prepared by the Ministries of Education, Health, Women and Children's Affairs and Agriculture to reach out to adult learners, whilst the Ministry of Agriculture could carry out the education on maternal and child health through its extension services programme. The extension officers are at the grassroots, interacting with the rural women, so could carry out this information better.

The provision of basic health facilities and antenatal and child health services calls for prioritisation in the disbursement of the health budget. For a developing country like Ghana, a reduction in public spending for tertiary care facilities, specialist training, and initiating clinical care with lower costeffectiveness will help increase the effectiveness of health spending [44]. There tends to be too much emphasis on clinical services other than primary health services. The reduction in tertiary health spending would save money for the provision of basic health services in the rural areas. These preliminary measures should precede the programming for health insurance, which would be the solution to the endemic financial predicament of the health sector and poor access to health services by the poor.

Besides, the strong correlation between maternal education and child health services calls for the establishment of a pilot project of integrating the two services. A strategy must be found to get the two integrated. Thereafter, a hypothesis could be formulated on the two events, based on the results, and an empirical survey conducted to assess the viability. Some strategies have been recommended. These include a basic and secondary school curricula that would expose the girl-child to the basic rudiments of child health, and the integrated programme among the four ministries to equip women with basic health care techniques of children through informal education and agricultural extension services programmes.

Finally, since poverty is the most serious factor affecting health conditions in general in the developing countries, efforts must be made to get women in gainful employment to improve upon their income base. Unemployed women, due to low or no formal education, must be equipped with vocational skills, and made accessible to minimum credit facilities that could give them economic empowerment.

\section{CONCLUSION}

Childhood mortality is quite high in Ghana, and measures are urgent to address it. In addressing the problem, the maternal factor comes into sharp focus, since maternal health is intricately linked with child health and vice-versa. In examining the relationship, the survey and other sources have shown succinctly the impact of mothers' education. A pilot project to integrate the education of women and maternal and child health is necessary, in order to serve as a basis for establishing its efficacy. To ensure the realisation of the objective of sustainable child health calls for a permanent source of health funding through a comprehensive health insurance, and the reduction in tertiary health expenditure to free funds for the provision of basic health services, especially for the rural areas. The empowerment of women through formal education and easy access to income sources are urgent prerequisites of sustainable child health. 
Buor, D.

Mothers education and childhood mortality in Ghana.

Health Policy: 64, 2003, nr. 3, p. 297-309

\section{ACKNOWLEDGEMENTS}

I am grateful to The Netherlands Foundation for the Advancement of Tropical Research (WOTRO), Den Haag, for funding this project; and to The Netherlands Institute for Health Services Research (NIVEL), Utrecht, for logistic support.

\section{TABLES AND FIGURES}

Table 1

Sampling errors for mortality statistics for women

\begin{tabular}{lrlll}
\hline Variable & Value $(R)$ & Standard error (S.E.) & Number of cases $(N)$ (Unweighted) & Relative error (R.E.) \\
\hline Neonatal mortality rate & 32.335 & 2.700 & 6635 & 0.084 \\
Infant mortality rate & 61.197 & 3.639 & 6644 & 0.059 \\
Child mortality rate & 52.382 & 3.213 & 6700 & 0.061 \\
Under-five mortality rate & 110.373 & 4.876 & 6709 & 0.044 \\
Postneonatal mortality rate & 28.862 & 2.360 & 6644 & 0.082 \\
\hline
\end{tabular}

Source: 1998 GDHS. p. 157 [19].

Table 2

Neonatal, post-neonatal, infant, child, and under-five mortality by mothers' education

\begin{tabular}{|c|c|c|c|c|c|}
\hline \multirow[t]{2}{*}{ Mothers' education } & \multicolumn{5}{|c|}{ Type of mortality } \\
\hline & $\mathrm{NN}$ & PNN & ${ }_{1} q_{0}$ & ${ }_{4} q_{1}$ & ${ }_{5} q_{0}$ \\
\hline No education & 33.8 & 32.3 & 66.1 & 69.3 & 130.8 \\
\hline Primary $^{\mathrm{a}}$ & 41.1 & 29.2 & 70.3 & 45.4 & 112.5 \\
\hline Middle/JSS ${ }^{\mathrm{b}}$ & 28.6 & 24.9 & 53.5 & 39.9 & 91.3 \\
\hline Secondary + & 10.5 & 26.3 & 36.8 & 23.9 & 59.8 \\
\hline Total & 32.3 & 28.9 & 61.2 & 52.4 & 110.4 \\
\hline
\end{tabular}

Source: GSS/MI, 1999, p.85 [23]; NN, neonatal mortality; PNN, post-neonatal mortality; ${ }_{1} q_{0}$, infant mortality; ${ }_{4} q_{1}$, child mortality; ${ }_{5} q_{0}$, under-five mortality.

a Primary education constitutes the first 6 years of formal schooling. The nursery or kindergarten school precedes it.

b Middle school was a bridge between primary school and secondary (high) school. It is now replaced by the Junior Secondary School (JSS).

\section{INFANT MORTALITY}

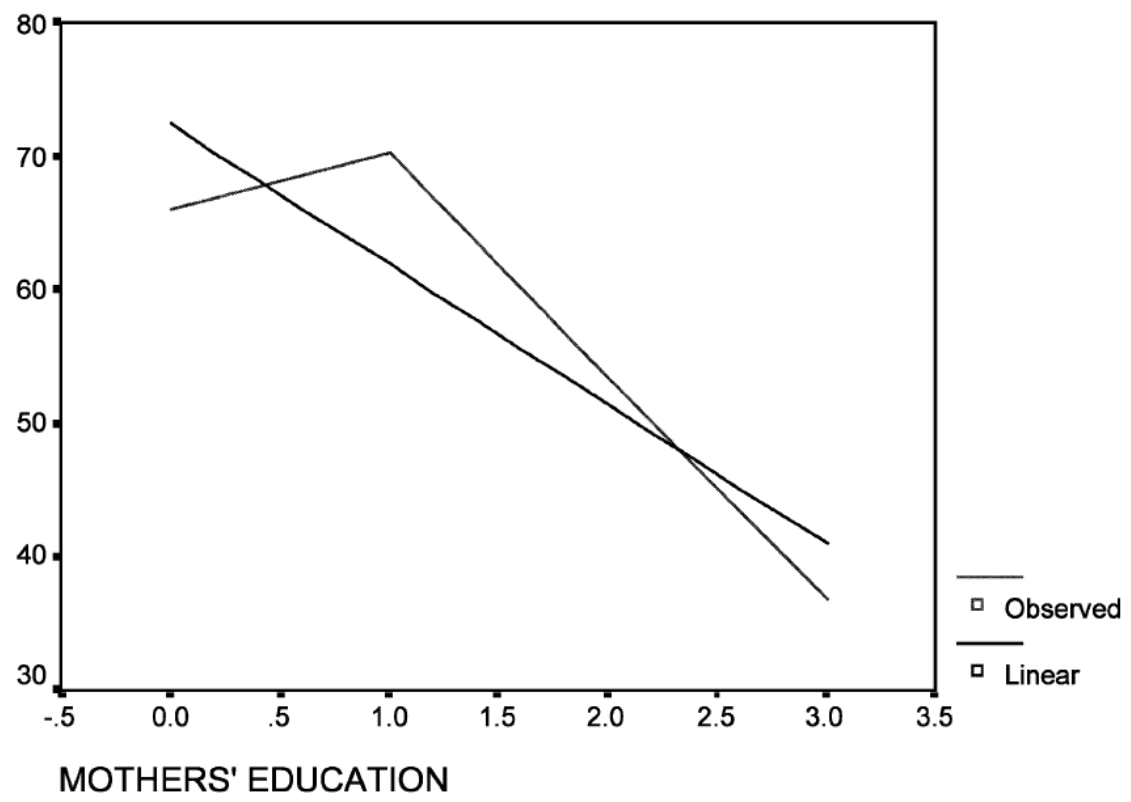

Fig. 1. Infant mortality and mothers' education. Source: Based on 1998 GDHS Data [23], February 2002. 


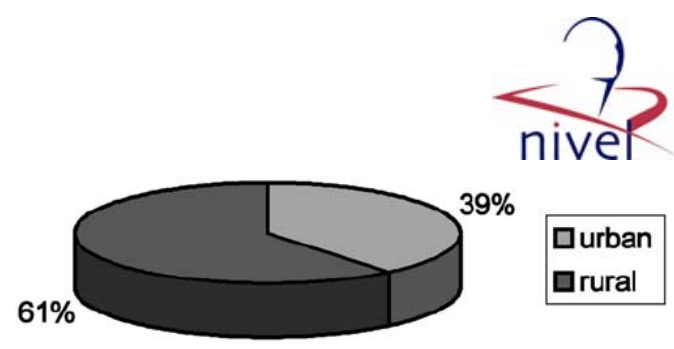

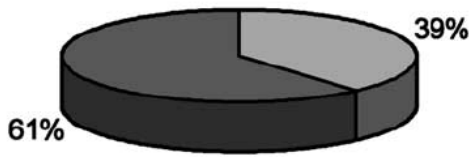

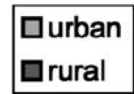

Fig. 2. Infant mortality by place of residence. Source: Based on GSS and MI, 1999, p. 85 [36].
Fig. 3. Under-five mortality by place of residence. Source: Based on GSS and MI, 1999, p. 85 [36].

Table 3

Percent distribution of births by number of tetanus toxoid injections mother received during pregnancy by mothers' education

\begin{tabular}{|c|c|c|c|c|c|}
\hline \multirow[t]{2}{*}{ Mothers' education } & \multicolumn{5}{|c|}{ Number of tetanus toxoid injections } \\
\hline & No injection & One dose & Two doses or more & Do not know/missing & Total \\
\hline No education & 26.6 & 26.2 & 46.3 & 0.9 & 100.0 \\
\hline Primary & 17.2 & 31.2 & 49.3 & 2.3 & 100.0 \\
\hline Middle/JSS & 10.8 & 31.9 & 56.1 & 1.2 & 100.0 \\
\hline Secondary + & 7.0 & 24.4 & 67.4 & 1.3 & 100.0 \\
\hline Total & 17.9 & 29.1 & 51.6 & 1.3 & 100.0 \\
\hline
\end{tabular}

Source: GSS and MI, 1999, p.95 [37].

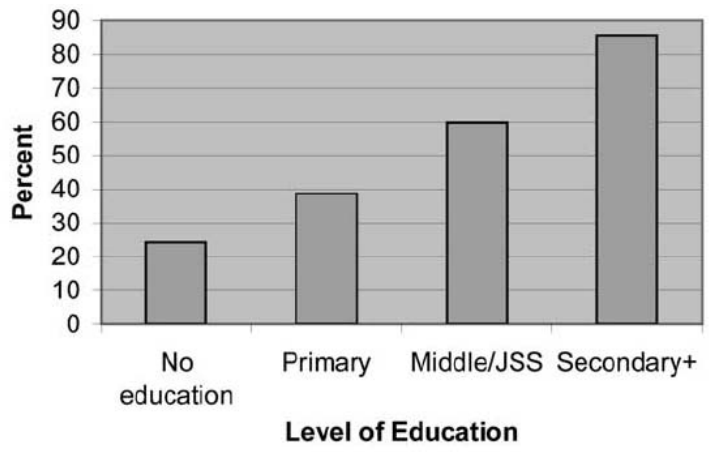

Fig. 4. Proportion of deliveries at a health facility by mothers' education. Source: Based on GSS and MI, 1999, p. 96 [38].

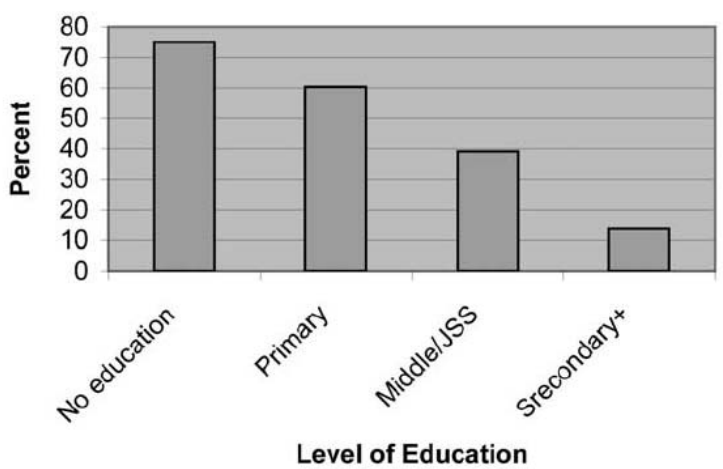

Fig. 5. Proportion of deliveries at home by mothers' education. Source: Based on GSS and MI, 1999, p. 96 [38].

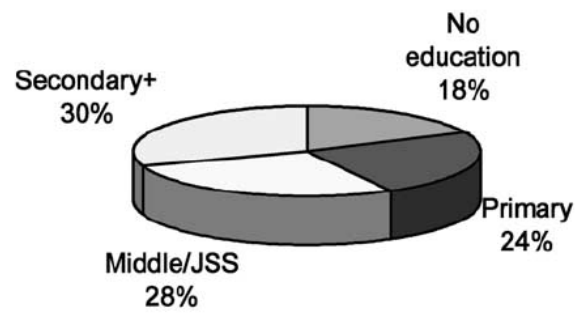

Fig. 6. Percentage of children fully vaccinated by mothers' education. Source: Based on GSS and MI, 1999, p. 104 [41].

\section{Table 4}

Percentage of children under-5 years suffering from diarrhoea, respiratory tract infection and fever by mothers' education

\begin{tabular}{llll}
\hline Mothers' education & \multicolumn{2}{l}{ Disease } & \\
\cline { 2 - 4 } & Diarrhoea & ARI & Fever \\
\hline No education & 21.3 & 15.3 & 28.1 \\
Primary & 20.7 & 13.6 & 25.8 \\
Middle/JSS & 14.5 & 12.9 & 25.4 \\
Secondary + & 8.2 & 10.0 & 30.9 \\
\hline
\end{tabular}

Source: GSS and MI, 1999, p.106-9 [42].

Table 5

Percentage of children under-5 years suffering from malnutrition by mothers' education

\begin{tabular}{|c|c|c|c|}
\hline \multirow{2}{*}{$\begin{array}{l}\text { Mothers' educa- } \\
\text { tion }\end{array}$} & \multicolumn{3}{|c|}{ Type of malnutrition } \\
\hline & $\begin{array}{l}\text { Height-for- } \\
\text { age }\end{array}$ & $\begin{array}{l}\text { Weight-for- } \\
\text { height }\end{array}$ & $\begin{array}{l}\text { Weight-for- } \\
\text { age }\end{array}$ \\
\hline No education & 13.1 & 1.9 & 8.1 \\
\hline Primary & 8.7 & 1.3 & 5.2 \\
\hline Middle/JSS & 6.7 & 1.2 & 2.9 \\
\hline Secondary + & 4.0 & 0.0 & 1.7 \\
\hline
\end{tabular}

Source: GSS and MI, 1999, p.120 [43]. 


\section{REFERENCES}

[1] The World Bank, World Development Indicators, 2000:16.

[2] WHO. The World Health Report, 2000:146.

[3] Hobcraft JN. Women's education. Child welfare and survival: a review of the evidence. Health Transition Review 1993(3):150-75.

[4] Raghupathy S. Education and the use of maternal health care in Thailand. Social Science and Medicine 1996;43(4):459-71.

[5] Swenson IE, Thang NM, Nhan VQ, Tieu PX. Factors related to the utilisation of pre-natal care in Vietnam. Journal of Tropical Medicine and Hygiene 1993;96(2):76 -85.

[6] Ghana Statistical Service and MI. GDHS 1998. Calverton, Maryland; 1994:101.

[7] Wyss K, Whiting D, Kilma P, Mclarty DG, Mtasina O, Tanner M, et al. Utilisation of government and private health services in Dar es Salaam. East African Medical Journal 1996;73(6):357-63.

[8] Pickett G, Hanlon J. Public health administration and practice. St. Louis: Times Mirror/Mosby College Publishing, 1990:541-2.

[9] Chernichovsky D, Meesook OA. Utilisation of health services in Indonesia. Social Science and Medicine 1986;23(6):611-20.

[10] Habib OS, Guilkey DK, Griffin CC, Popkin BMK. The demand for primary health services utilisation in Southern Iraq: a household survey. International Journal of Epidemiology 1986:359-403.

[11] Ghana Statistical Service. Population and housing census, preliminary results. Accra-Ghana; 2000.

[12] Ojanuja DN, Gilbert C. Women's access to health care in developing countries. Social Science and Medicine 1992;35(4):613-7.

[13] The World Bank, World Development Indicators, 2000:82.

[14] Bleek W. Family and family planning in Southern Ghana. In: Oppong C, editor. Sex roles, population and development in West Africa. London: Heinemann; 1987. p. 139.

[15] Criel B, Van-der-Stuyft $P$, Van-Lerberghe W. The Bwamanda hospital insurance scheme: effective for whom? A study of its impact on hospital utilisation patterns. Social Science and Medicine 1999;48(7):897-911.

[16] Ghana Statistical Service and MI. GDHS 1998. Calverton, Maryland; 1999:145-6.

[17] Ghana Statistical Service and MI. GDHS 1998. Calverton, Maryland; 1999:148.

[18] Ghana Statistical Service and MI. GDHS 1998. Calverton, Maryland; 1999:81-2.

[19] Ghana Statistical Service and MI. GDHS 1998. Calverton, Maryland; 1999:157.

[20] Jejeebhoy SJ. Women's education, autonomy, and reproductive behaviour: experience from developing countries. New York: Oxford University Press, 1995.

[21] Heggenhougen HK. Perceptions of health-care options and therapy-seeking behaviour. In: John Cleland and Allan G Hill, editors. The Health Transition: Methods and Measures. Cambridge University Press; 1989 (Book 3). Pp. 133-146.

[22] Katherine BL, George WM. The differential effect of mothers' education on mortality of boys and girls in India. Population Studies 1991;45(2):203-19.

[23] Bhuiya A, Stretfield K. Mothers' education and survival of female children in a rural area of Bangladesh. Population Studies 1991;45(2):235-52.

[24] Caldwell JC, Reddy PH, Caldwell P. The social component of mortality decline: an investigation in South India employing alternative methodologies. Population Studies 1983(37):185 -205.

[25] Dujardin B, Clarysse G, Criel B, De Brouwere V, Wangata N. The strategy of risk approach in antenatal care: evaluation of the referral compliance. Social Science and Medicine 1995;40(4):52935.

[26] Bor W, Najman JM, Andersen M, Morrison J, Williams G. Socio-economic disadvantage and child mortality: an Australian longitudinal study. Social Science and Medicine 1993;36(8):1053-61.

[27] Yach D, von-Schirnding YE. Towards a higher priority for health on the development agenda. Public Health Review 1994;22(3-4):339-74.

[28] Caldwell JC. Routes to low mortality in poor countries, 1986. Population and Development Review 1986;12:171-220.

[29] Mensch B, Lentzener H, Preston S. Socio-economic differentials in child mortality in developing countries. United Nations. New York: Department of International Economic and Social Affairs, 1985:19-56.

[30] Ghana Statistical Service and MI. GDHS 1998. Calverton, Maryland; 1999:83.

[31] The World Bank. World Development Report. 2000:286-287.

[32] Ghana Statistical Service and MI. GDHS 1998. Calverton, Maryland; 1999:102.

[33] Ghana Statistical Service and MI. GDHS 1998. Calverton, Maryland; 1999:xxi. 
Buor, D.

Mothers education and childhood mortality in Ghana.

Health Policy: 64, 2003, nr. 3, p. 297-309

[34] Ghana Statistical Service and MI. GDHS 1998. Calverton, Maryland; 1999:91.

[35] Ghana Statistical Service and MI. GDHS 1998. Calverton, Maryland; 1999:114.

[36] Ghana Statistical Service (GSS) and Micro International (MI). Ghana Demographic and Health Survey 1998. Calverton, Maryland; 1999:85.

[37] Ghana Statistical Service (GSS) and Micro International (MI). Ghana Demographic and Health Survey 1998. Calverton, Maryland; 1999:95.

[38] Ghana Statistical Service (GSS) and Micro International (MI). Ghana Demographic and Health Survey 1998. Calverton, Maryland; 1999:120.

[39] Ghana Statistical Service (GSS) and Micro International (MI). Ghana Demographic and Health Survey 1998. Calverton, Maryland; 1999:123.

[40] Ghana Statistical Service (GSS) and Micro International (MI). Ghana Demographic and Health Survey 1998. Calverton, Maryland; 1999:117.

[41] Ghana Statistical Service (GSS) and Micro International (MI). Ghana Demographic and Health Survey 1998. Calverton, Maryland; 1999:104.

[42] Ghana Statistical Service (GSS) and Micro International (MI). Ghana Demographic and Health Survey 1998. Calverton, Maryland; 1999:106-109.

[43] Ghana Statistical Service (GSS) and Micro International (MI). Ghana Demographic and Health Survey 1998. Calverton, Maryland; 1999:120.

[44] The World Bank. World Development Report, Oxford: Oxford University Press, 1993:13. 